\title{
Programme planning methods for enterprise activities in the territorially concentrated construction complex
}

\author{
Margarita Panteleeva ${ }^{l, *}$, and Svetlana Borozdina ${ }^{l}$ \\ ${ }^{1}$ Moscow State University of Civil Engineering, 129337, 26, Yaroslavskoye Shosse, Moscow, Russia
}

\begin{abstract}
This article is dedicated to the problem of the lack of a systematic approach in the creation of financial and business plans at construction enterprises. The current policy in the field of long-term management does not imply the existence of a strictly regulated procedure. As a rule, this process each time has a new structure and a new toolkit. And given the current trend towards clustering in the construction sector, such a situation could adversely affect the further development of the entire industry. The article suggests a description of the multi-level management system of a construction enterprise. This system is based on comprehensive programs that allow, through a centralized management function, to streamline the process of solving the basic tasks facing the construction company in the framework of the entire construction industry. The program method proposed by the authors is an addition to the already used planning methods and allows to overcome the difficulties that arise in connection with the territorial concentration of the construction complex.
\end{abstract}

\section{Introduction}

Organizational and structural features of the development of integrated programs have not received sufficient coverage in the economic literature. Only a few works on this subject expressed quite general provisions. For example: "Complex state programs are developed for the effective implementation of the most important goals of social development, solving the most complex state problems, which, based on the analysis of current trends in the development of industries and interindustry complexes, can not be solved without a specially organized structural change and a number of special measures necessary for overcoming the inertia of the existing ties and proportions fixed by the organizational structure of the planning and management process " [1].

We will analyze the features of the development of complex programs from the point of view of developing a financial and economic plan for the activity of a construction enterprise.

\section{Materials and methods}

${ }^{*}$ Corresponding author: angela-1309.m@yandex.ru, anteikom@yandex.ru 
Compilation of any type of financial and economic plans, especially at the sectoral level, is carried out on the basis of a multi-level system. Let us describe its main features. It consists of a number of interacting elements, which have to make decisions in the process of functioning. Elements are understood as organizations or subdivisions of organizations involved in the development of financial and business plans, for example, various divisions of the company, departments or its subsidiaries. Elements of the system are hierarchical in the sense that some of them manage other. [2,3]

Between elements of a multi-level planning system, there are vertical and horizontal links. Vertical connections are caused by the processes of purposeful coordination of the activity of the elements of the lower levels on the part of the corresponding elements of the higher levels of the hierarchy. As a rule, vertical links exist between elements of neighboring levels, and horizontal links correspond to the exchange of information between elements of the same level.

Each element of the multi-level planning system is developing a plan for its object (department, division, etc.), and subordinate cells of this cell are oriented to "parts" of this object. The allocation of "parts" can occur on the basis of territorial, production, functional characteristics and their combinations, for example, some element may be engaged in the development of a plan for the development of a system of material incentives for employees of a separate subsidiary.

When moving from below-up to the levels of the hierarchy, there is a consistent increase in the generality of the examination. Each element views its object in a more general form than it is considered in aggregate by the cells subordinate to it, and the plan developed by the element concerns relatively more general characteristics of the development of the object, and the plans of subordinate cells specify it for their "parts". Accordingly, the interactions of elements of different levels have a certain character. Information coming to some element describes a plan developed by a downstream cell in a rather general form from the point of view of the sides most important for the higher-level element, that is, when information is transferred to higher levels of the hierarchy, information is aggregated. So, some element can develop a plan for the production of twenty kinds of products (in kind) and only report on the value of the total output calculated in terms of value.

In turn, and the control signals are related to the general aspects of the functioning of the elements of the subordinate levels.

The indicators that the elements of the planning system operate on can be divided into three groups: input, output and internal (intermediate).

Input includes indicators reflecting the status of cells of a lower level of the hierarchy subordinate to a given cell element, as well as control parameters by means of which the higher-level element affects the behavior of this element of the system. The output refers to the indicators that carry information to the higher-level element about the state of this element, as well as the control parameters by which this element affects the behavior of the subordinate cells of the lower level of the hierarchy. Internal indicators, together with input and output, describe in sufficient detail from the point of view of this element the corresponding planning object. They determine, for example, how fully the goals of the element are realized in one or another variant of the plan, they serve as the basis for the formation of output indicators. Internal indicators are not directly affected by higher levels. The whole complex of indicators should comprehensively describe the planned system of measures for the development of a construction enterprise, evaluate its effectiveness and the consequences of implementing various programs. The main groups of indicators, which operate elements of a multi-level planning system:

1. input informative indicators;

2. input control indicators;

3. internal indicators; 
4. Output informative indicators;

5. output control indicators.

One of the main features of multi-level systems is the consistent aggregation of information on the hierarchy levels. The output indicators arriving at the higher level element describe the state of the child element in a rather general form from the point of view of the parties most important to the element of the higher level. Accordingly, the coordinating signals refer to the most common aspects of the functioning of the elements of the subordinate level. This generates relative freedom in the activities of the elements of the planning system. By the values of the output indicators, it is impossible to establish the exact values of the intermediate and input information indicators, and, consequently, directly control them. The choice of the final values of intermediate and output control indicators is presented to the elements of the planning system, in which their role as the decisive centers in the process of drawing up the plan is manifested.

\section{Results}

Consider some element of the system, which forms a plan for the development of excavation sites at various construction sites for projects in general. He reports only the total volume of production, measured in a cube. $\mathrm{m}$ (output indicator). From the downstream cells, he receives data on the volumes of production they are supposed to produce separately according to the types of soil (input indicators). Then the indicators of the production volumes of each of the soil types for the projects as a whole (it is assumed that the element calculates them) are internal.

The right to choose the final value of internal indicators (however, as well as the output managers) belongs to the very element of the system, of course, if they are not obtained from input control indicators on the basis of direct calculations. Input control indicators, imposing restrictions on the possible values of intermediate, as a rule, leave this element a certain freedom in choosing their values, that is, for a multi-level planning system, the relative decentralization of the decision-making process is characteristic.

All elements of a multi-level planning system in the course of their activities should be guided by certain goals. On the basis of these goals, both formal and informal criteria are constructed to assess the various options of their respective planning decisions and choose the most appropriate and effective ones.

The process of drawing up a financial and economic plan by a multi-level system can be simplified as follows. Each element carries out the development of a plan for its object, the elements exchange information about the result of the activity. Based on these messages, both the initial work is performed and the earlier decisions and calculations are corrected. When the process ends, within each element is a "ready" part of the financial and economic plan relating to the object corresponding to it. These parts are interconnected by input and output indicators.

Thus, the completed financial and economic plan appears in the form of a set of parts, linked by inputs and outputs, each of which is located in the corresponding element of the plan development system.

A multilevel planning system is described above in general. One of its main features is the relative decentralization of the process of making planned decisions, which makes it possible to significantly reduce the amount of information circulating in the system, to give the cell activities a creative character, and to increase their individual responsibility for the quality of the plan. At the same time, the relative independence of cell activity generates the possibility of inconsistencies between parts of the plan, which puts forward high demands on the coordination mechanism. 
In the course of drawing up the plan, there can be problems that can not be effectively solved within the existing planning system, or it is inappropriate because of the significance or uncertainty of the necessary cycles for coordinating planned decisions. Complex programs can be developed to solve such problems. When developing a program, the element of the planning system violates the distribution of functions established in the system and takes upon itself the realization of a part of the functions of the cells of the subordinate levels of the hierarchy subordinate to it, ie, a certain centralization of functions for the development of the plan takes place. Changes can have different character. It is possible, for example, that for some part of the planning object corresponding to the given cell, the superior element takes on only the decision-making function to choose the direction of its development, leaving this cell with the information function associated with finding possible alternatives. And it is possible that this part of the object is completely withdrawn from the field of the cell, and the plan for it is developed by a higher element. However, in any case, the decisionmaking function is centralized. As a result, some of the internal indicators come out of the control of the cells of the lower levels of the hierarchy, which are subordinated to the "program-developing" element, and it has the opportunity to consider the system of indicators in unity sufficient to solve the planned task in a complex way.

Let's consider an example. Let a certain subdivision or a subsidiary company, among other planned tasks, develop a plan for the production of $\mathrm{N}$ types of building materials for residential development of new microdistricts. In the central and planning body it reports the indicator of the total volume of production, measured in conventional units. The volume of production of each type (internal indicators) is determined within the general constraint based on the demand forecast, which is based on the accumulated experience and knowledge of the state of affairs of traditional consumers. Let the scientific and technological progress in the chemical industry branches lead to the discovery and development of a new way of producing a certain construction structure. [4] We call its product A. Moreover, one of the k types of the above production $(\mathrm{k}<\mathrm{N})$ should be used as the raw material. Production possibilities of the product A old methods are limited by the scarcity of the corresponding raw materials. At the same time, the new method is effective and opens the prospect of meeting the demand for this product. Thus, the task arises of developing a plan for introducing a new method for the production of product A into the construction industry. This task is connected with the task of determining the output of $\mathrm{k}$ types of products of our division. Where should the task be solved? In our division it can be solved only by focusing on the old spheres of use. If we address this task to the central planning body, then it will not have enough indicators, since it has only an indicator of total production of $n$ types that can not be determined from its conventional units. A possible way out of the situation is to deviate from the distribution of functions fixed by the existing organizational structure and to transfer the function of adopting a planned decision on the volumes of production of the required $\mathrm{m}$ types of products to the central planning body. Naturally, the same must be transferred to the relevant construction company and the production planning function for the product A. So, the central planning body will consider a program that can be conditionally called "The program to meet the needs of the construction industry in product A", it is clear that its core is the implementation new technology. In this program, based on the restrictions on the possible amount of capital investments, reserves of necessary natural resources, etc., the volume of production of A will be determined separately for the old and new methods, the indicators characterizing the development of the raw materials base for these industries, the volume and structure of the various types resources. In particular, the necessary production volumes of each of the $t$ types of products are determined. These indicators are reported to the construction company, where they can be considered as the minimum possible volumes of production. That is, in this case, the functions of planning the production of each of the $t$ types of products are centralized only in terms of determining the lower boundary (necessary 
for the implementation of the program being developed). A construction company should focus on the needs of the entire construction industry. It can plan the satisfaction of the demand of a new consumer both at the expense of increasing production volumes in comparison with those planned for a traditional consumer and by transferring it to alternative types of products that are not in short supply in this situation. It is likely, however, that in order to meet the demand of the country's economy, product A will require such a large number of products of the said enterprise that it will endanger the construction industry with this product [5].

In this case, it becomes necessary to consider the problem of introducing a new method for the production of product $\mathrm{A}$ as a subproblem of a broader problem that can be called constructive-chemical. Accordingly, the program developed for its solution will look like. In it, the scale of the introduction of new technology in the chemical industry is determined in close relationship with the solution of production and design problems: changes in the volume of production of old types of building structures, development of new types and development of their production, changes in the structure of consumption of structures in the construction industry. Naturally, the decision-making functions for the main of these types are transferred by the relevant construction enterprises to the central planning body. Including the said construction company transfers there the function of developing the production plan is no longer $\mathrm{N}$, but $\mathrm{M}$ types of products. In this program, it may be planned not only to increase the output of product A, but also to substantially change the entire base of structural elements.

If the non-program parts of the plan appear in the form of relatively isolated blocks coordinated only by the entrances and exits of the blocks, each of which is located at the corresponding cell of the planning system, then the program in the form of a single set of interrelated indicators "is" for the element that develops it.

Programs can, if necessary, thread several levels of the hierarchy, covering a different number of elements of each level. In this regard, we can identify the vertical and horizontal aspects of the centralization of functions. In the first case, the functions of cells of several consecutive levels are centralized; in the second - the functions of a number of cells of the same level. As a rule, both these aspects are present in the program.

In relation to a single element of a multi-level planning system, the program can be internal and external. We will call the program internal if its goals are directly related to the realization of some function of the given element. We will call the program external, if the centralized function of this element is related to the resource support for the realization of the goal to which the program is directed. Let, for example, the planning for the development of a certain territory be a function of a certain cell of the system, and the superior element, having decided on the development of a program whose purpose is to intensify the development of this region, assumes the fulfillment of this function. Then for the indicated cell the program will be internal. If at the same time the function of this element is centralized, connected with the planning of the production of some resource necessary for the successful development of the given territory, then for this element the program will have an external character.

\section{Discussion}

So, the development of programs is connected with the strengthening of centralization in decision-making processes in certain areas of sectoral planning [6,7]. The programs are developed to solve those problems that can not be solved at the moment effectively on the basis of the existing (sectoral and territorial) division of functions in the organizational structure of the planning system and the methods adopted for coordinating planning decisions. Difficulties in coordinating some set of planned decisions that correspond to 
different elements of the planning system are overcome in the development of programs by moving away from the distribution of functions fixed by the organizational structure and concentrating these decisions on the superior element, which considers them in the necessary unity. In principle, any element of a multi-tiered system can decide to develop a comprehensive program if, in the course of its activities, it feels necessary to centralize the functions of subordinate elements of the lower levels $[8,9,10]$.

Note that the existing planning system has a relatively small degree of decentralization in the design of the plan. This leads to excessive overloading of the elements of the upper levels of information coming to them, which they are often unable to process quickly and qualitatively, which leads to a decrease in the efficiency of the entire system [11]. A change in this situation is naturally possible in the turbidity of the strengthening of decentralization (in particular, the increase in the weight of horizontal connections between cells, as indicated by a series of studies), while improving the coordination mechanism. A complex role in the solution of this issue will also be played by comprehensive programs that, centralizing the adoption of decisions on certain issues, may allow us to weaken centralization in solving others. Then some element of the system is part of its planned tasks, for which the established coordination mechanism is satisfactory, will be solved non-programmatically, and others through the development of programs. At the same time, due to the reduction of information flows corresponding to the non-program part of the plan, the element will be able to pay more attention to programs, not simply formal control over their indicators, but rather considering various options for implementing program objectives, comprehensively evaluating them and choosing the most effective one.

\section{Conclusion}

So, the program can be defined as a set of planned activities aimed at solving a certain problem, the development of which is associated with a specially organized centralization of functions in a multi-level planning system.

Thus, the software method is a natural addition to the existing planning methods and allows in certain cases to overcome the difficulties caused by the territorial and sectoral structural features of the decision-making process.

Let's analyze on the basis of the stated provisions on the relationship between program and non-program parts of the long-term plan. As is known, a number of authors suggest considering the long-term plan in the form of a set of integrated programs, while others argue against a complete "programming" of the long-term plan. They believe that programs should act as elements of a long-term plan that has an off-program part. More correctly from the standpoint of the above approach is the second concept. The proposal of a full "programming" of a long-term plan means a refusal when developing it from the hierarchical principles of building a planning system, which is very problematic. Therefore, the existence of mutually complementary program and non-program parts of the long-term plan for the economic and social development of the Russian construction industry seems to be natural.

\section{References}

1. V.L. Tambovtsev, A.A. Tikhomirov, Organizatsiya $i$ upravleniye kompleksnymi programmami (MGU, Moskva,1982)

2. M.V. Mel'nik, Analiz $i$ otsenka sistem upravleniya na predpriyatiyakh (Finansy i statistika, Moskva, 1990)

3. M.S. Panteleeva, S.M. Borozdina, Internet-zhurnal Naukovedeniye 5(18) (2013) 
4. A.N. Asaul, B.M. Karpov, V.B. Perevyazkin, M.K. Starovoytov, Modernizatsiya ekonomiki na osnove tekhnologicheskikh innovatsiy (ANO IPEV, Sankt-Peterburg, 2008)

5. N.V. Gorodnova, T.N. Yegorushkina, L.L. Kifa, N.B. Kurshakova, N.S. Kurshakova, M.S. Panteleyeva, Problemy ekonomiki $i$ upravleniya predpriyatiyami, otraslyami, kompleksami: monografiya. Kniga 28 (Izdatel'stvo TSRNS, Novosibirsk, 2015)

6. A. Mottaeva, A. Zheltenkov, E3S Web of Conferences, 33, 01038 (2018)

7. M.S. Panteleeva, S.M. Borozdina, MATEC Web Of Conferencies 106, 08047 (2017)

8. M.S. Panteleeva, S.M. Borozdina, MATEC Web Of Conferencies 106, 08048 (2017)

9. A.R. Leybkind, B.L. Rudnik, A.A. Tikhomirov, Organizatsionnyye osobennosti razrabotki kompleksnykh programm (Vestnik Mosk.universiteta. Ser. Ekonomika, Moskva, 1996)

10. N. Brookes, N. Ivanišević, A. Lukasiewicz, T. Sainati, C. lo Storto, Special Purpose Entities in Megaprojects, Transport and Urban Development, Action megaproject TU 1003 (University of Leeds, 2015) ISBN 978-0-9576805-3-1

11. J. Ćetković, M. Knežević, N. Ivanišević, S. Rutešić, Central European Journal of Spatial and Landscape Planning, Terra Spectra Stu 1/2010, 47-55 (2010) ISSN 1338-0370 